\title{
Low-waste fermentation-derived organic acid production by bipolar membrane electrodialysis-an overview
}

\author{
Éva Hülber-Beyer ${ }^{1}$ (1) $\cdot$ Katalin Bélafi-Bakó ${ }^{1} \cdot$ Nándor Nemestóthy $^{1}$
}

Received: 10 February 2021 / Accepted: 24 May 2021 / Published online: 5 June 2021

(c) The Author(s) 2021

\begin{abstract}
Organic acids, e.g, citric acid, fumaric acid, lactic acid, malic acid, pyruvic acid and succinic acid, have important role in the food industry and are potential raw materials for the sustainable chemical industry. Their fermentative production based on renewable raw materials requires innovatively designed downstream processing to maintain low environmental impact and resource efficiency throughout the production process. The application of bipolar membranes offers clean and effective way to generate hydrogen ions required for free acid production from its salt. The water dissociation reaction inside the bipolar membrane triggered by electric field plays key role in providing hydrogen ion for the replacement of the cations in organic acid salts. Combined with monopolar ion-exchange membranes in a bipolar membrane electrodialysis process, material flow can be separated beside the product stream into additional reusable streams, thus minimizing the waste generation. This paper focuses on bipolar membrane electrodialysis applied for organic acid recovery from fermentation broth.
\end{abstract}

Keywords Alkali recycling $\cdot$ Downstream process $\cdot$ Electromembrane process $\cdot$ Organic acid recovery

\section{Introduction}

The preference toward renewable and bio-based chemicals is higher and higher nowadays, and this fact encourages and inspires scientists to develop and fine-tune biotechnological organic acid production. The key focus of research is on the reduction of raw material costs (Dörsam et al. 2017; Sawant et al. 2018), on the optimization of microorganisms (Yin et al. 2015; Johansen 2017; Li et al. 2021), yield (Liu et al. 2017), and last but not least recovery methods (LópezGarzón and Straathof 2014).

Organic acids are produced industrially by either fermentation or chemical synthesis (Pinazo et al. 2015). The main advantage of synthesis is that the resulting product is usually of high purity and concentrated (Ai and Ohdan 1997; Gao et al. 2018). But the high energy demand and the use of expensive catalysts (Sang et al. 2019), in some cases toxic, environmentally hazardous reagents (Prikaznov et al. 2011; Solmi et al. 2019), represent great shortcomings of synthetic

Éva Hülber-Beyer

beyer.eva@mk.uni-pannon.hu

1 Research Group On Bioengineering, Membrane Technology and Energetics, University of Pannonia, 8200 Veszprém, Hungary methods. Microbial cell factories work under mild conditions in aqueous solutions. The main drawback of fermentation is the recovery of the product from a complex matrix. Innovative techniques, however, can overcome that hurdle.

Several membrane-based processes have proven effective in the extraction of valuable materials from complex matrices (Castro-Muñoz et al. 2018; Stoller et al. 2018). The experience gained in membrane technology for the treatment of industrial and agricultural wastewater can also be applied to the fermentation industry. Among others, bipolar membrane electrodialysis has been successfully used to treat industrial wastewater with high salinity (Tian et al. 2019).

Bipolar membrane electrodialysis (ED-BPM) is a promising technique for the recovery of bio-products that exist in ionic form in a certain $\mathrm{pH}$ range. Since supplementary substances for organic acid recovery are not required-unlike the traditional process - there is even the possibility to recycle the separated aqueous process streams in biotechnological procedures that are sensitive to chemical load. 


\section{Acids in the scope of this study}

The physicochemical properties of organic acids vary with the number of carbon atoms, carboxyl groups, or additional functional groups like oxo- or hydroxy substituents (Rawn and Ouellette 2018). Hereby, we present a selection of organic acids of food significance, among which mono-, di- and tricarboxylic acids, oxo- and hydroxyl-acids, saturated and unsaturated acids also can be found. These represent a broad variety of organic acids having significance or potential in the large scale chemical industry as well (Aurich et al. 2012).

Pyruvic acid also referred to as 2-oxo-propanoic acid has gained interest in the food industry as a potential fat burner that can accelerate the fatty acid metabolism in humans in the form of calcium pyruvate (Stanko et al. 1992). Special diets supplemented with pyruvic acid result in improved leg exercise endurance (Stanko et al. 1990), and lower cholesterol (Stanko et al. 1994). It is also a valuable substrate for the enzymatic production of amino acids such as L-tryptophan, L-tyrosine, and L-dihydroxyphenylalanine (L-DOPA) (Li et al. 2001).

Lactic acid (2-hydroxy-propanoic acid) is used in the food industry as a preservative, $\mathrm{pH}$ regulator, and tasteenhancing additive (Bai et al. 2003). Lactic acid-producing microorganisms are capable to form lactic acid from pyruvate.

Citric acid or 2-hydroxypropane-1,2,3-tricarboxylic-acid is used extensively in carbonated beverages to provide taste and complement fruit and berry flavors. It also increases the effectiveness of antimicrobial preservatives. Over $99 \%$ of the citric acid produced worldwide is the result of fermentation processes (Berovic and Legisa 2007).

Succinic acid (butanedioic acid) is produced both synthetically and via fermentation. Succinic acid of biotechnological origin is used in the food industry as an acidulant, as a flavoring agent, and as an antimicrobial agent. Furthermore, fermentation-derived succinic acid has the potential to become a large-volume commodity chemical (Zeikus et al. 1999).

Fumaric acid (trans-butenedioic acid) is a four-carbon dicarboxylic acid that is 1.5 times more acidic than citric acid. Therefore, it is commonly used as a food acidulant and beverage ingredient. Additionally, fumaric acid is widely used in the feed industry as an antibacterial agent and a physiologically active substance. It is also a valuable intermediate in the preparation of edible products, such as L-malic acid and L-aspartic acid. With the increasing market share of L-aspartic acid and L-malic acid in sweeteners, beverages, and other health food areas, the worldwide demand for fumaric acid and its derivatives grows each year (Xu et al. 2012).
Malic acid (2-hydroxybutanedioic acid), just like succinic acid and fumaric acid, is a four-carbon dicarboxylic acid and an intermediate in the citric acid cycle. As it possesses a greater acid taste and better taste retention than citric acid, malic acid is mainly used as an acidulant and flavor enhancer in beverages, candy, and food. It can be produced enzymatically from fumaric acid or biosynthetically from carbohydrates via fermentation (Chi et al. 2016).

Some important physical and chemical properties of the above-listed acids can be found in Table 1 .

\section{Fermentation processes for organic acid production}

Organic acid production by microorganisms is related to their carbon source catabolism and energy management (Sanchez and Demain 2008; Trchounian and Trchounian 2019). Simple sugars can be used as carbon sources. Polysaccharides, primarily starch and cellulose are good substrates for acid production but generally, hydrolysis must be integrated into the process beforehand (Carta et al. 1999; Passoth and Sandgren 2019). Glycolysis is the first step in the breakdown of glucose to extract energy for cell metabolism. Pyruvate formed at the end of glycolysis may enter the citric acid cycle if it is present in the cell. The intermediates of the citric acid cycle are organic acids like citric acid, succinic acid, malic acid, etc. (Kertes and King 1986). Metabolic evolution resulted in potential organic acid overproducing microbial strains from various natural habitats (Sanchez and Demain 2008).

In the last century, labor and time-consuming efforts have been taken to screen microorganisms for the overproduction of organic acids for future industrial applications (Yu et al. 2020). The screening work was successful in many cases, and potent wild-type strains were collected and preserved in strain deposits. The understanding of the metabolic pathways, the genetic background and regulation behind them led to novel, high-performance screening techniques, that accelerated the efficiency of finding new efficient strains,

Table 1 Physical and chemical properties of organic acids in the scope of this study

\begin{tabular}{llll}
\hline Acid name & $\begin{array}{l}\text { Solubility in } \\
\text { water at } 20{ }^{\circ} \mathrm{C} \\
(\mathrm{g} / \mathrm{L})\end{array}$ & $\mathrm{pK}_{\mathrm{a}}$ values & $\begin{array}{l}\text { Melting point } \\
\left({ }^{\circ} \mathrm{C}\right)\end{array}$ \\
\hline Citric acid & 592 & $3.14 ; 4.77 ; 6.39$ & 153 \\
Fumaric acid & 4.9 & $3.03 ; 4.54$ & 287 \\
Lactic acid (DL) & Miscible & 3.86 & 18 \\
Malic acid (DL) & 558 & $3.40 ; 5.11$ & $128-132$ \\
Pyruvic acid & Miscible & 2.50 & 12 \\
Succinic acid & 58 & $4.16 ; 5.61$ & $185-190$ \\
\hline
\end{tabular}


even from a large number of genetically modified mutants (Sanchez and Demain 2008; Yin et al. 2015).

For the biotechnological production of organic acids, three possible implementations are given (Li et al. 2001):

- direct fermentation method;

- resting cell method;

- enzymatic method starting from a precursor.

At the end of all the processes, acids are usually present in an aqueous solution with a $5-20 \mathrm{w} \%$ concentration.

Glucose is a basic carbon source in organic acid fermentation research. In Table 2, we collect some effective microorganisms that have great potential in industrial organic acid production, and we have indicated the achievable broth concentration in direct fermentation processes carried out with them, starting from glucose.

The application of bacteria, yeasts or filamentous fungi together with the complex nitrogen and carbon sources in the fermentation medium greatly influence the rheological properties of the broth from which recovery has to be performed (Charles 1978; Dhillon et al. 2013).

The $\mathrm{pH}$ of the fermentation and type of base used in the process are also of interest, as they can determine which recovery methods can be used, how the steps of the process can be integrated and whether or not side streams can be recycled. For example, ammonia, sodium hydroxide or potassium hydroxide can be recovered by bipolar membrane electrodialysis (Molnár et al. 2010; Xue et al. 2015; van Linden et al. 2020), whereas calcium carbonate cannot be.

The optimization of fermentation processes has to support a feasible product recovery to become an alternative for chemical synthesis.

\section{Downstream processing of fermentation media}

Downstream process is a sequence of separation processes applied to purify specialty chemicals such as organic acids from biotechnological production (Whittington 1990). Organic acids in the scope of this study are produced as extracellular metabolites. Their recovery therefore typically involves the following functions (López-Garzón and Straathof 2014):

1. Clarification: removal of large particles, microbial cells, and their debris.

2. Primary recovery: separation of the product from bulk aqueous solution and from major impurities.

3. Counterion removal: replacement of the cation of organic acid salt by $\mathrm{H}^{+}$to get carboxylic acid (if required).

4. Concentration/purification: partial removal of the solvent achieving concentration; removal of remaining impurities.

Figure 1 shows possible downstream processing sequences.

Clarification and concentration include classical methods in all direct fermentation processes. Clarification is usually accomplished by centrifugation or microfiltration (Whittington 1990; Gryta and Tomczak 2015), or a combination of the two methods, whereas concentration means solvent evaporation by distillation or crystallization (Gryta and Waszak 2016; Karp et al. 2018). They give a frame to downstream operation: the first step is the separation of

Table 2 Some organic acid overproducing strains, and product concentration at the end of direct fermentation-the listed strains utilized glucose as carbon source in the indicated fermentations

\begin{tabular}{llll}
\hline Organic acid & Producing strain & $\begin{array}{l}\text { Organic acid concentration in } \\
\text { the fermentation broth }\end{array}$ & Reference \\
\hline Pyruvic acid & recombinant Escherichia coli & $62 \mathrm{~g} / \mathrm{L}$ & (Zelić et al. 2003) \\
& Torulopsis glabrata IFO 0005 multiauxotrophic yeast & $67.8 \mathrm{~g} / \mathrm{L}$ & (Miyata and Yonehara 1996) \\
Lactic acid & Lactobacillus casei LA-04-1 & $112.5 \mathrm{~g} / \mathrm{L}$ & (Ding and Tan 2006) \\
& Corynebacterium glutamicum & $95 \mathrm{~g} / \mathrm{L}$ & (Okino et al. 2005) \\
& Rhizopus oryzae NRRL 395 & $60 \mathrm{~g} / \mathrm{L}$ & (Bulut et al. 2004) \\
Citric acid & Aspergillus niger PM1 & $121 \mathrm{~g} / \mathrm{L}$ & (Papagianni et al. 1999) \\
& Candida lipolytica Y1095 & $78.5 \mathrm{~g} / \mathrm{L}$ & (Rane and Sims 1993) \\
Succinic acid & Actinobacillus succinogenes ZT-130 & $33.8 \mathrm{~g} / \mathrm{L}$ & (Lee et al. 1999) \\
& Anaerobiospirillum succiniproducens ATCC 29,305 & $35.2 \mathrm{~g} / \mathrm{L}$ & (Riscaldati et al. 2000) \\
Fumaric acid & Rhizopus arrhizus NRRL 1526 & $38 \mathrm{~g} / \mathrm{L}$ & (Zhou et al. 2002) \\
& Rhizopus oryzae ATCC 20,344 & $37.2 \mathrm{~g} / \mathrm{L}$ & (Knuf et al. 2013) \\
& Aspergillus oryzae NRRL 3488 & 30.2 & (Zhang et al. 2011)
\end{tabular}




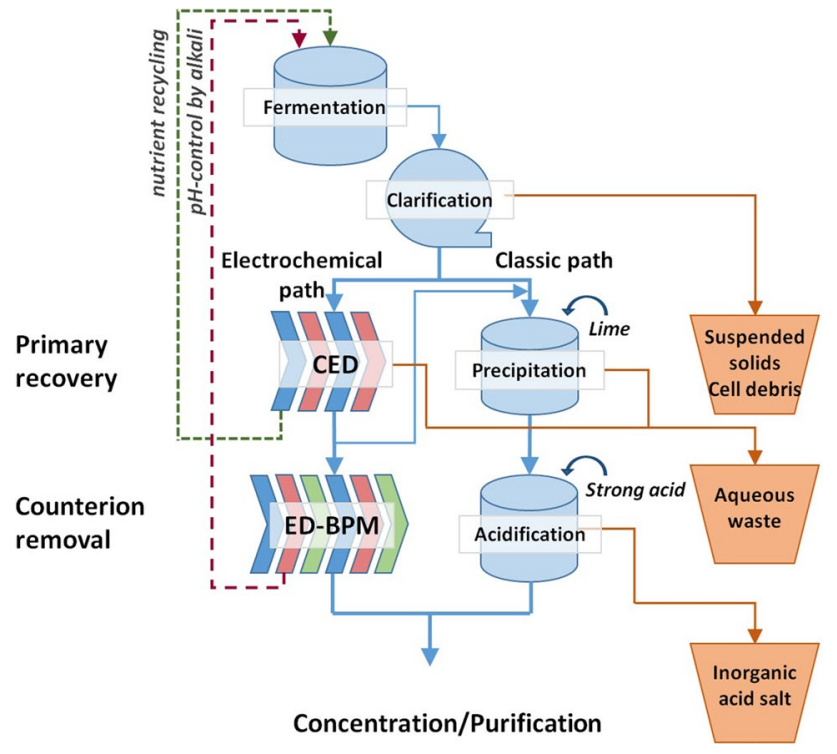

Fig. 1 Downstream processing sequences for the recovery, purification, and upgrading of fermentative carboxylic acids (CED $=$ conventional electrodialysis; ED-BPM = bipolar membrane electrodialysis)

cell mass and solids, and the last step, the removal of the solvent to get a concentrated or solid product from its pure solution. The steps between the two can vary widely. The challenge is to get rid of the complex soluble matrix-with as much recycled substance as possible to minimize waste and new material need, and to apply the desired counterion in the product (special salt or acidic form). The recovery process should be tailored for the organic acid in question to achieve the optimum result.

\section{Primary recovery of organic acids}

After the clarification of fermentation broth, the filtered carboxylate solution still contains numerous impurities such as sugars and salts remaining from the fermentation feed, and fermentation by-products, such as proteins and undesired carboxylic acids, secondary metabolites. In all recovery strategies, the bulk of the impurities are removed by selectively transferring the product to another phase.

The oldest technique to realize primary recovery is precipitation. For example, citric acid, the first organic acid produced on a large scale by fermentation, is precipitated from the clarified broth with the addition of calcium hydroxide in a classical industrial plant. The formed insoluble calcium citrate can be thus separated from bulk water and impurities (Wang et al. 2020). The precipitate is filtered off and washed. The next step is acidification using sulfuric acid which yields soluble citric acid and a large amount of gypsum as a by-product. Only the precipitation method cannot be applied in all cases. Although the calcium salt of pyruvic acid, for instance, is poorly soluble in water, the instability of pyruvate under alkaline conditions hinders the applicability of precipitation ( $\mathrm{Li}$ et al. 2001). A well-designed process for the primary recovery of pyruvic acid is a distillation process with high energy costs. The alternative possibilities for precipitation are solvent extraction, ion exchange, and electrodialysis (ED).

\section{Conventional electrodialysis}

Electrodialysis is an electromembrane process. The key components of that process are ion-exchange membranes. The particular role of ion-exchange membranes is to transport and separate ionic components selectively (Strathmann et al. 2013). Regarding their function, they are classified as:

- cation-exchange membranes-that contain fixed negatively charged ions, thus having a selective permeability for cations;

- anion-exchange membranes-they are enriched with fixed positively charged ions, and have a selectivity for the transmission of anions;

- bipolar membranes-which consist of a cation- and an anion-exchange membrane laminated together, the close proximity of the fixed opposite charged ionic ligands creates a special interfacial interaction, that promotes water dissociation under low electric voltage.

Separation by electrodialysis is based on the ionic state of carboxylic acids in a certain $\mathrm{pH}$ range. By using ionselective membranes in electric field, the carboxylate anion is recovered from fermentation broth while large molecules and solutes with opposite charge or no charge at all are retained. The $\mathrm{pH}$ of the feed solution should be adjusted to the experimentally determined optimum of electroseparation (Novalic et al. 1995).

The transport of an ion through an ion-exchange membrane or within an electrolyte solution occurs under the driving force of the electrochemical potential gradient of the ion, which is a function of the electrical potential and the chemical potential. Chemical potential shows dependence on the given species, the activity of the species, temperature, and pressure (Strathmann et al. 2013). The charge number of the ion also influences the migrating driving force; hence, in the case of di- and tri-acidic organic acids, the $\mathrm{pH}$ is of special interest. Direct current is used to create electric potential difference on the two sides of the membranes.

The conventional electrodialysis (CED) is a reliable process for more than half a century for primary recovery and concentration application. A conventional electrodialysis unit consists of a series of alternating anion- and cationexchange membranes arranged between two electrodes. When electrical potential difference between the electrodes 
is established, the anions migrate toward the anode. They are able to pass through the anion-exchange membrane but are retained by the cation-exchange membrane. The cations move in a similar but countercurrent way. The overall result is that an electrolyte is concentrated in alternate compartments while in the other compartments ions are depleted. Experiments for pyruvic acid (Zelić and Vasić-Rački 2005), lactic acid (Bailly et al. 2001), citric acid (Novalic et al. 1995), and succinic acid (Glassner et al. 1995) with CED primary recovery have been performed showing general applicability of the method. In the case of malic acid, conventional electrodialysis was tested to recover it as a byproduct from an industrial fermentation process involved in the manufacturing of alcoholic beverages and proved to be effective (Lameloise et al. 2009). Enzymatic conversion of fumaric acid to L-malic acid was successfully integrated with CED to selectively recover malic acid from the reaction solution, after the precipitation and recycling of the remained fumaric acid (Bélafi-Bakó et al. 2004). Though references for CED as a recovery process for fumaric acid are scarce, another integrated technique for ammonium-Lmalate production from ammonium-fumarate (Sridhar 1988) gives some clues that a CED process for primary recovery could be implemented for fumaric acid as well.

\section{Counterion removal}

In optimized fermentation processes, $\mathrm{pH}$ is usually one of the key parameters. The applied $\mathrm{pH}$ range varies for each microorganism, but life phenomena can be considered inhibited below pH 2 (Sharma et al. 2016) and above pH 12-13 (Preiss et al. 2015) with some rare exceptions. Due to the weak acidity of the organic acids in question, there is a certain degree of dissociation i.e., salt formation even in a fermentation performed at low $\mathrm{pH}$. In the final product, the metal ion content is usually regulated by quality standards and regarded as an impurity. The efficiency of the applied technology for replacing counterions with hydrogen greatly influences the quality of the produced organic acid.

In precipitation-being the classical primary recovery technique for organic acids-classical counterion removal is the displacement of the organic acids from their insoluble salts by a strong acid. The chosen acid shall form another insoluble salt with the cation, $\mathrm{Ca}^{2+}$ or $\mathrm{Mg}^{2+}$ in general (López-Garzón and Straathof 2014) while the free acid becomes a solute. Sulfuric acid is the most cost-effective inorganic acid for the purpose. The inorganic salt byproduct, e.g., gypsum, is formed in comparable quantities as the product itself. In the case of weakly soluble acids, e.g., fumaric acid, the operating temperature of acidification is high to keep the free acid in dissolved state while the inorganic precipitate is filtered off (Xu et al. 2012); thus, in addition to by-product formation, the energy consumption is high, too.

All in all the recognition of the water dissociation catalyzing behavior of bipolar membranes under electric voltage (Frilette 1956) gave an advantageous possibility to provide the hydrogen ions from pure water, as scientists have recognized it at the outset of the research on it (Nagasubramanian et al. 1977). Recently, the development of ion-exchange membranes concerning their chemical and mechanical resistance shifted the focus from basic research to industrial usability.

\section{Bipolar membrane electrodialysis}

Industrial bipolar membrane electrodialysis technologies are already available for industrial wastewater treatment to valorize aqueous salt streams-either organic or inorganic - by generating acidic and caustic by-products. Being an additive-free possibility to influence the $\mathrm{pH}$ of an aqueous solution, the food industry utilizes specially designed types of ED-BPM equipment for adjusting the acidity of edible fluids (specifically sugar syrups, fruit and vegetable juices, wines, sauces, and tomato paste) (Bazinet et al. 1998). To inhibit undesired enzymatic reactions-e.g., the enzymatic browning of cloudy apple juice-the process is also in use. Shifting the $\mathrm{pH}$ from the enzyme-optimum in the highly acidic range causes partial, irreversible denaturation of the enzyme thus activity loss; then, the $\mathrm{pH}$ is readjusted to the original value in the same equipment but another cell stream. The treatment enhanced the color of cloudy apple juice during storage without modifying the flavor (Tronc et al. 1998).

Industrial ED-BPM organic acid production plants have been first established in 1995 in the USA, and several others followed in Japan and Europe (Bailly 2002). Those, however, use organic acid salts of high purity as raw material for acidification.

The main cost of membrane-based processes is the membranes themselves and the specific energy requirement (Castro-Muñoz et al. 2018). The recent results of membrane development should be taken into account in the industrial implementation, thus the maintenance costs (Zhao et al. 2021b), energy demand (Yan et al. 2018) and product purity (Liao et al. 2020; Yan et al. 2020) can be beneficially affected. Specific energy consumption from experimental results, however, can be taken as an indicator of the economic viability of the process (Zhao et al. 2021a).

A theoretical calculation was carried out by Wang et al. to determine whether ion exchange or bipolar electrodialysis is the economically better choice for counterion removal in the production of gluconic acid as a model organic acid (Wang et al. 2011). They introduced two factors into their calculations: an environmental factor and a membrane factor. Their results show that the ion-exchange 
process is more economical when environmental considerations are less important. However, when this factor increases in a medium range, the combined ion exchangeelectrodialysis system is more advantageous. According to Wang et al., bipolar membrane electrodialysis will become truly competitive when environmental costs rise and bipolar membrane prices fall.

The performances of the ED-BPM process can be evaluated in terms of the specific energy consumption $\left(\mathrm{kW} \cdot \mathrm{kg}^{-1}\right)$, the recovery rate of the organic acid (\%) and the average current efficiency (\%). The detailed calculation method is described in (Sun et al. 2017).

Organic acids can be produced directly from clarified fermentation medium by ED-BPM. Compared to the processing of an organic acid solution from primary recovery process, more significant membrane fouling may occur in such cases. The cell-free solution contains several different anions, and the effect of their presence on the recovery of fumaric acid was investigated in one-, two- and threecomponent model solutions at different current densities (Prochaska and Woźniak-Budych 2014). The other anions were present in an order of magnitude lower concentration than the fumarate ions, but the recovery rate was still significantly reduced at lower current densities, especially in the case of tertiary model solution with acetate and chloride ions. Comparing data from the fumarate-acetate binary model solution and the fumarate-acetate-chloride tertiary model solution, it was interesting to observe that while the recovery ratio of fumaric acid was reduced by one-third in the tertiary solution compared to the binary solution, the recovery ratio of acetic acid was not affected significantly by chloride ions. In the same study, the EDBPM of fermentation broth pretreated with nanofiltration was investigated. In addition to fumaric acid, cordycepic acid and glycerol as a substrate for bioconversion were present in this broth. The bipolar electrodialysis was not selective for fumaric acid and cordycepic acid, but retained glycerol almost completely in the diluate stream. In another research, Kim et al. demonstrated that a singlestep ED-BPM procedure may be more suitable than the two-step CED + ED-BPM recovery method of lactic acid directly from microfiltered fermentation broth (Kim and Moon 2001). A three-chamber arrangement was found to be suitable for this purpose, provided that a properly selected cation- and anion-exchange membrane is used.

In Table 3, some promising results are presented for organic acid recovery using a model or real fermentation broth feed. However, in the majority of the works listed in which real fermentation broth has been tested, the ED-BPM technique is applied primarily as a counterion removal step after a partially purifying/concentrating CED pretreatment.

The following cell configurations have been tested (Fig. 2).
- Two compartments with cation-exchange and bipolar membranes where soda is removed from the salt compartment through the cation-exchange membrane (CEMBPM).

- Two compartments with anion-exchange and bipolar membranes where the acid is removed from the salt compartment through the anion-exchange membrane (AEMBPM);

- Three compartments anion-exchange, cation-exchange, and bipolar membranes where the organic acid and the counterions are removed from the salt compartment through the anionic and cationic membrane, respectively (AEM-CEM-BPM).

These configurations are fundamentally different. In a CEM-BPM process, the salt stream is fed between the CEM side of the BPM and the CEM, and only the cations have to be transported through a membrane. This process is only adequate if the acid salt is in a pure solution and the goal is to produce free acid (Fig. 2a). The pure alkaline solution obtained on the concentrate side can be used for $\mathrm{pH}$ control in fermentation, as it was demonstrated in an integrated continuous lactic acid fermentation-ED system (Wang et al. 2013).

In an AEM-BMP process, the organic acid anions have to pass through the anion-selective membrane, the salt stream is fed between the AEM side of the BPM and the AEM. The anions pass through the anion-selective membrane and combine with the $\mathrm{H}^{+}$generated on the CEM side of the BPM. This method gives a possibility to get rid of impurities in the feed stream. If the AEM and the separation parameters are chosen carefully also anionic impurities of some kind can be removed (Fig. 2b). When the concentration of organic acid anions becomes low enough, the BPM-generated hydroxide ions start migrating through the anion-exchange membrane. In the acidic concentrate compartment, they recombine with hydrogen ions to water. This futile phenomenon reduces the current efficiency and thus limits the increase in the recovery rate (Kim and Moon 2001).

In the three-compartment configuration, both the acid anions and the cations must pass through a membrane (Fig. 2c). That increases the necessary energy input for operation, but it should be mentioned that there are two product streams if we consider that an uncontaminated alkali solution is generated simultaneously which can be recycled into the fermentation process as in the CEM-BPM configuration. In that case, the leakage of water ions is inhibited due to the membrane arrangement.

In a study on pyruvic acid recovery, the three-compartment ED-BPM was tested on model solution and two, differently pretreated real fermentation broths (Zelić and Vasić-Rački 2005). The ED-BPM with cell-free fermentation broth performed poorly compared to ED-BPM with 


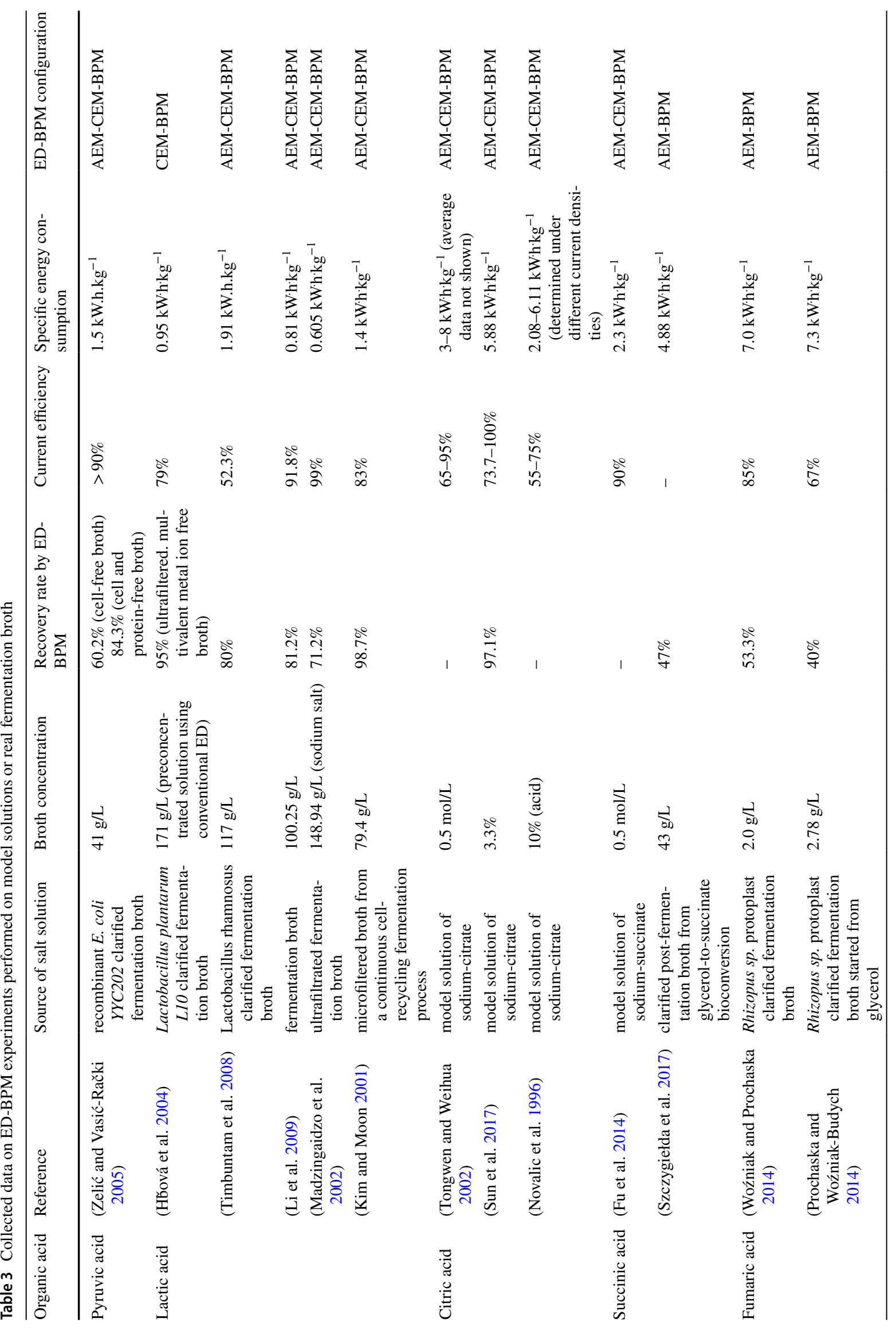


model solution. The recovery ratio was $30 \%$ lower, the specific energy consumption was $10 \%$ higher, though current efficiency was only slightly reduced. The underperformance was due to the effect of biological substances-such as proteins and cell debris-in the broth. This is supported by the fact that the results of the experiment with similar but ultrafiltered fermentation broth, the performances were comparable with those obtained with model solutions.

Timbuntam et al. (Timbuntam et al. 2008) compared the three ED-BPM configuration for lactic acid separation. According to their findings, the AEM-BPM gives the highest current efficiency and the lowest energy consumption. The use of a size-exclusion anion-selective membrane (PC 100D, PCA Gmbh. Germany) prevented the permeation of negatively charged higher molecular weight metabolites and of other substances with no charge, e.g., carbohydrates along with the obvious retention of positively charged substances.

In contrast, Kim et al. (Kim and Moon 2001) found that a three-compartment ED-BPM was the most effective configuration for lactic acid recovery. They also compared the three configurations, but went further and checked the performances of different ion-exchange membranes.

The three different configurations were tested for citric acid production too (Tongwen and Weihua 2002), and it was stated that for citric acid recovery the CEM-BPM variant is the optimal choice. The use of three-compartment version for citrate acidification was found to be particularly costly, but it should be noted that the results shown here were obtained with just one production cell between electrode compartments. For a ED-BPM stack with many production cells, the exact values for energy consumption and current efficiency may be changed due to the cell number.

In the study on succinic acid recovery, three-compartment ED-BPM performed better than two-compartment variants reaching the highest current efficiency and moderate specific energy consumption (Fu et al. 2014).

For fumaric acid recovery from real fermentation broth, the AEM-BPM and CEM-BPM configurations were tested and it was concluded that the AEM-BPM process fits for the purpose (Prochaska and Woźniak-Budych 2014).

Malic acid was successfully recovered from model solution applying a CEM-BPM ED stack with high acid recovery ratio and acceptable specific energy consumption (Lameloise and Lewandowski 2012). However, similar experiments using real solution-a concentrate from CED of an alcoholic fermentation waste water stream-specific energy consumption significantly increased by $50 \%$ because of the presence of anionic impurities.

The key components determining the efficiency of the electrodialytic recovery process are the applied membranes. In laboratory research dedicated to analyze organic acid recovery from a production method, the possibility is not necessarily given to choose from a wide range 
Fig. 2 Different ED-BPM configurations tested for organic acid recovery from fermentation broth

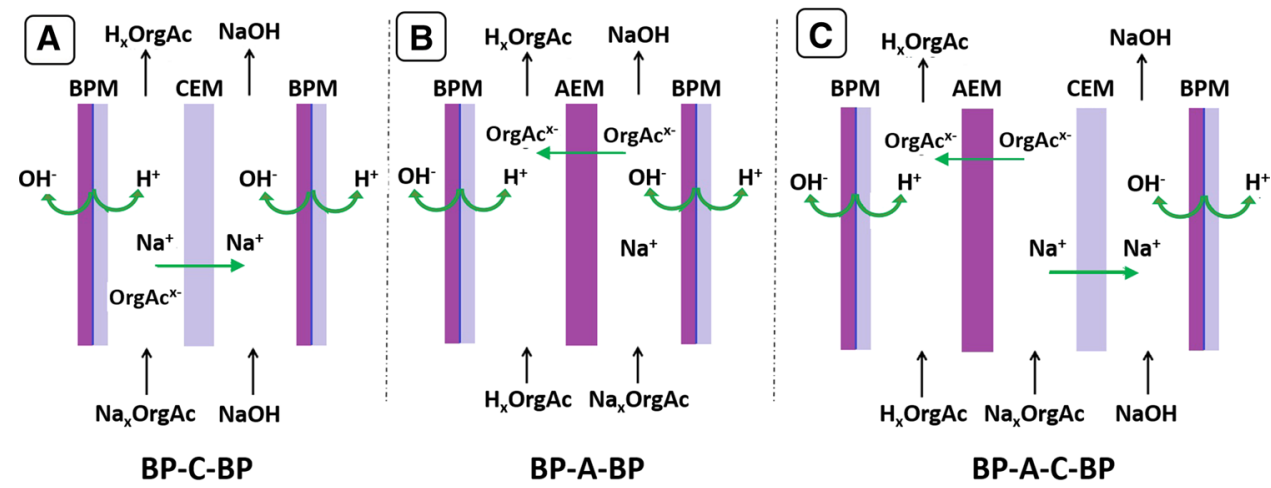

of ion-exchange membranes. The appropriate decision is generally the purchase of commercially available products. The use of Neosepta membranes by Astom Corporation (previously named Tokuyama) is widespread in research (Novalic et al. 1996; Madzingaidzo et al. 2002; Hø̌ová et al. 2004; Zelić and Vasić-Rački 2005; Timbuntam et al. 2008; Lameloise and Lewandowski 2012; Sun et al. 2017), and it is also worth mentioning the ion-exchange membranes from the ACS Ltd. (Zelić and Vasić-Rački 2005; Prochaska and Woźniak-Budych 2014; Woźniak and Prochaska 2014; Szczygiełda et al. 2017)

The overall productivity of the process could be enhanced with a coupled-research on membrane development with special regard to the selectivity of ion-exchange membranes. For example, Cybulski et al. (Cybulski et al. 2018) produced pyruvic acid successfully from glycerol and also obtained significant amounts of $\alpha$-keto-glutaric acid as a by-product. Both acids are valuable, and their effective separation might be feasible with CED or ED-BPM by the reasoning above.

The most common base used for $\mathrm{pH}$ regulation during fermentation is sodium hydroxide, with the mobile monocharged sodium cation. The divalent cations present in broth are mainly substrates for the producing microorganism and as such are represented in a definitely lower concentration compared to sodium. In a continuous fermentation process, the ion-depleted ED-BPM diluate stream containing carbohydrates and other substrates could be recycled, and the retention of divalent cations in that case could be beneficial. The CEMs are worth testing for divalent cation rejection (Kim and Moon 2001).

Through the bipolar membrane, ideally, no mass transport occurs. However, its electrical resistance plays a very important role in determining the operating costs. For a process to be operated at low energy consumption, membranes with low electrical resistance are required (Kim and Moon 2001). The contribution of the electric resistance of bipolar membranes is the highest to the overall resistance of the ED stack. The bipolar membranes got interest in substantially different application fields too since they can couple different $\mathrm{pH}$ environments into a single electrochemical device
(Oener et al. 2020). BPMs with an interfacial catalyst layer between the laminated AEM and CEM were found to have smaller electric fields at the interface compared to samples with no added catalyst. A comprehensive numerical simulation model showed that the damping of the electric field in BPMs with a catalyst layer is a result of a higher water dissociation product $\left(\mathrm{H}^{+} / \mathrm{OH}^{-}\right)$flux, which neutralizes the net charge density of the CEM and AEM layer (Yan et al. 2018).

In ED-BPM, some of the membranes are exposed to high alkalinity during operation. The chemical stability of membranes is also the subject of research (Bulejko et al. 2017) and has great importance in the safe and long-term applicability of ion-exchange and bipolar membranes.

Even with well-chosen membranes, fouling is a problem to be solved. The process design of ED-BPM is closely related to that of the conventional electrodialysis using the sheet flow stack design. In intermembrane space, the fluid is circulated at a high velocity. A turbulent flow could be advantageous, but this increases the energy input. The insertion of specially designed spacers in transmembrane cells leads to obstructions that result in a strongly eddying motion of the circulated fluids (Probstein et al. 1972); thus, the laminar film on the membrane surface becomes thinner, and fouling can be prevented. The thickness of spacers has an optimal range in which the mass transfer coefficient only slightly decreases (Káňavová et al. 2015).

\section{Conclusions}

Biotechnological processes are considered as sustainable ways, methods to produce organic acids on large scale and these products mean alternatives to widely used platform chemicals that originate currently from fossil sources. Application of bipolar membrane electrodialysis in the downstream processing operations eliminates the inorganic waste generation. Another beneficial property of the application is its integrability into effective primary commodity management. 
Three possible operational configurations have been recognized depending on the types of monopolar membranes used in combination with the bipolar membrane. The twocompartment configurations, where only one type of monopolar ion-exchange membrane is used, result in an acidic and an alkaline stream. If the applied monopolar membrane is cation-exchange type, the process is appropriate for the counterion removal from pure salt solution combined with alkali regeneration. In the case of combination with anionexchange membranes, the organic acid anion can be removed from its original solution selectively, and the $\mathrm{pH}$ of the diluate stream shifts in the highly alkaline range during operation. In the three-compartment configuration, three separate aqueous streams are produced: product solution containing the organic acid in acidic form, alkali solution containing the cations (generally sodium) and hydroxide ions, and the diluate stream in which neutral materials and ionic components with high molecular size are retained. The most effective utilization of substances can be achieved by the application of the letter configuration although its energy consumption is relatively higher.

The fact that experiments with real solutions are underperforming compared to tests with model solutions highlights the importance of these investigations. They can shed light on unpleasant phenomena and unexpected effects for which a solution strategy should be developed in future.

In future, an overview on the progress made in the development of bipolar membranes in different application areas may be desirable to consider their potential application in ED-BPM processes for organic acid recovery.

Well-designed and multidisciplinary research on the EDBPM processes optimized for the recovery of organic acids directly from fermentation broth will certainly result in competitive industrial methods, with low energy consumption, a stable long-term operation, and with no significant membrane fouling. The environmental benefits of that processes are beyond question.

Acknowledgements The research work was supported by the National Research, Development and Innovation Fund Project K 119940 entitled "Study on electrochemical effects on bioproduct separation by electrodialysis."

Funding Open access funding provided by University of Pannonia.

\section{Declarations}

Conflict of interest On behalf of all authors, the corresponding author states that there is no conflict of interest.

Open Access This article is licensed under a Creative Commons Attribution 4.0 International License, which permits use, sharing, adaptation, distribution and reproduction in any medium or format, as long as you give appropriate credit to the original author(s) and the source, provide a link to the Creative Commons licence, and indicate if changes were made. The images or other third party material in this article are included in the article's Creative Commons licence, unless indicated otherwise in a credit line to the material. If material is not included in the article's Creative Commons licence and your intended use is not permitted by statutory regulation or exceeds the permitted use, you will need to obtain permission directly from the copyright holder. To view a copy of this licence, visit http://creativecommons.org/licenses/by/4.0/.

\section{References}

Ai M, Ohdan K (1997) Oxidative dehydrogenation of lactic acid to pyruvic acid over iron phosphate catalyst. Appl Catal A Gen 150:13-20

Aurich A, Specht R, Müller RA et al (2012) Microbiologically produced carboxylic acids used as building blocks in organic synthesis. Subcell Biochem 64:391-423

Bai DM, Wei Q, Yan ZH et al (2003) Fed-batch fermentation of Lactobacillus lactis for hyper-production of L-lactic acid. Biotechnol Lett. https://doi.org/10.1023/A:1026276925649

Bailly M (2002) Production of organic acids by bipolar electrodialysis: realizations and perspectives. Desalination 144:157-162

Bailly M, Roux-De Balmann H, Aimar P et al (2001) Production processes of fermented organic acids targeted around membrane operations: design of the concentration step by conventional electrodialysis. J Memb Sci 191:129-142

Bazinet L, Lamarche F, Ippersiel D (1998) Bipolar-membrane electrodialysis: applications of electrodialysis in the food industry. Trends Food Sci Technol 9:107-113

Bélafi-Bakó K, Nemestóthy N, Gubicza L (2004) A study on applications of membrane techniques in bioconversion of fumaric acid to L-malic acid. Desalination 162:301-306

Berovic M, Legisa M (2007) Citric acid production. Biotechnol Annu Rev 13:303-343

Bulejko P, Stránská E, Weinertová K (2017) Electrochemical and mechanical stability of ion-exchange membranes in alkaline solution. Chem Pap 71:1303-1309

Bulut S, Elibol M, Ozer D (2004) Effect of different carbon sources on $\mathrm{L}(+)$-lactic acid production by Rhizopus oryzae. Biochem Eng J 21:33-37

Carta FS, Soccol CR, Ramos LP, Fontana JD (1999) Production of fumaric acid by fermentation of enzymatic hydrolysates derived from cassava bagasse. Bioresour Technol 68:23-28

Castro-Muñoz R, Barragán-Huerta BE, Fíla V et al (2018) Current role of membrane technology: from the treatment of agro-industrial by-products up to the valorization of valuable compounds. Waste Biomass Valorization 9:513-529

Charles M (1978) Technical aspects of the rheological properties of microbial cultures. Advances in Biochemical Engineering, vol 8. Springer, Berlin, Heidelberg, pp 1-62

Chi Z, Wang ZP, Wang GY et al (2016) Microbial biosynthesis and secretion of 1-malic acid and its applications. Crit Rev Biotechnol 36:99-107

Corona-González RI, Bories A, González-Álvarez V, Pelayo-Ortiz C (2008) Kinetic study of succinic acid production by Actinobacillus succinogenes ZT-130. Process Biochem 43:1047-1053

Cybulski K, Tomaszewska-Hetman L, Rymowicz W et al (2018) Yarrowia lipolytica application as a prospective approach for biosynthesis of pyruvic acid from glycerol. Chem Pap 72:3077-3083

Dhillon GS, Brar SK, Kaur S, Verma M (2013) Rheological studies during submerged citric acid fermentation by aspergillus niger in stirred fermentor using apple pomace ultrafiltration sludge. Food Bioprocess Technol 6:1240-1250 
Ding S, Tan T (2006) l-lactic acid production by Lactobacillus casei fermentation using different fed-batch feeding strategies. Process Biochem 41:1451-1454

Dörsam S, Fesseler J, Gorte O et al (2017) Sustainable carbon sources for microbial organic acid production with filamentous fungi. Biotechnol Biofuels. https://doi.org/10.1186/s13068-017-0930-x

Frilette VJ (1956) Preparation and characterization of bipolar ionexchange membranes. J Phys Chem 60:435-439

Fu L, Gao X, Yang Y et al (2014) Preparation of succinic acid using bipolar membrane electrodialysis. Sep Purif Technol 127:212-218

Gao Z, Chen W, Chen X et al (2018) Study on the isomerization of maleic acid to fumaric acid without catalyst. Bull Korean Chem Soc 39:920-924

Glassner DA, Elankovan P, Beacom DR, Berglund KA (1995) Purification process for succinic acid produced by fermentation. Appl Biochem Biotechnol. https://doi.org/10.1007/BF02933412

Gryta M, Tomczak W (2015) Microfiltration of post-fermentation broth with backflushing membrane cleaning. Chem Pap 69:544-552

Gryta M, Waszak M (2016) Application of vacuum membrane distillation for concentration of organic solutions. Chem Pap. https:// doi.org/10.1515/chempap-2016-0002

Hǿová V, Melzoch K, Rychtera M, Sekavová B (2004) Electrodialysis as a useful technique for lactic acid separation from a model solution and a fermentation broth. Desalination 162:361-372

Johansen E (2017) Future access and improvement of industrial lactic acid bacteria cultures. Microb Cell Fact. https://doi.org/10.1186/ s12934-017-0851-1

Káňavová N, Krejčí A, Benedeková M et al (2015) Mass transfer examination in electrodialysis using limiting current measurements. Chem Pap 69:553-559

Karp EM, Cywar RM, Manker LP et al (2018) Post-fermentation recovery of biobased carboxylic acids. ACS Sustain Chem Eng 6:15273-15283

Kertes AS, King CJ (1986) Extraction chemistry of fermentation product carboxylic acids. Biotechnol Bioeng 28:269-282

Kim YH, Moon SH (2001) Lactic acid recovery from fermentation broth using one-stage electrodialysis. J Chem Technol Biotechnol $76: 169-178$

Knuf C, Nookaew I, Brown SH et al (2013) Investigation of malic acid production in aspergillus oryzae under nitrogen starvation conditions. Appl Environ Microbiol 79:6050-6058

Lameloise ML, Lewandowski R (2012) Recovering l-malic acid from a beverage industry waste water: Experimental study of the conversion stage using bipolar membrane electrodialysis. J Memb Sci 403:196-202

Lameloise ML, Matinier H, Fargues C (2009) Concentration and purification of malate ion from a beverage industry waste water using electrodialysis with homopolar membranes. J Memb Sci 343:73-81

Lee PC, Lee WG, Kwon S et al (1999) Succinic acid production by Anaerobiospirillum succiniciproducens: effects of the $\mathrm{H} 2 / \mathrm{CO} 2$ supply and glucose concentration. Enzyme Microb Technol 24:549-554

Li Y, Chen J, Lun SY (2001) Biotechnological production of pyruvic acid. Appl Microbiol Biotechnol 57:451-459

Li J, Chen Z, Wang P, et al (2009) Separation of L-lactic acid from fermentation broth by bipolar membrane electrodialysis. Chinese J Bioprocess Eng

Li C, Ong KL, Cui Z et al (2021) Promising advancement in fermentative succinic acid production by yeast hosts. J Hazard Mater. https://doi.org/10.1016/j.jhazmat.2020.123414

Liao J, Chen Q, Pan N et al (2020) Amphoteric blend ion-exchange membranes for separating monovalent and bivalent anions in electrodialysis. Sep Purif Technol. https://doi.org/10.1016/j.seppur. 2020.116793
Liu G, Luo H, Wang $\mathrm{H}$ et al (2014) Malic acid production using a biological electrodialysis with bipolar membrane. J Memb Sci 471:179-184

Liu J, Li J, Shin H, dong et al (2017) Protein and metabolic engineering for the production of organic acids. Bioresour Technol 239:412-421

López-Garzón CS, Straathof AJJ (2014) Recovery of carboxylic acids produced by fermentation. Biotechnol Adv 32:873-904

Madzingaidzo L, Danner H, Braun R (2002) Process development and optimisation of lactic acid purification using electrodialysis. J Biotechnol 96:223-239

Miyata R, Yonehara T (1996) Improvement of fermentative production of pyruvate from glucose by Torulopsis glabrata IFO 0005. J Ferment Bioeng 82:475-479

Molnár E, Nemestóthy N, Bélafi-Bakó K (2010) Utilisation of bipolar electrodialysis for recovery of galacturonic acid. Desalination 250:1128-1131

Nagasubramanian K, Chlanda FP, Liu KJ (1977) Use of bipolar membranes for generation of acid and base - an engineering and economic analysis. J Memb Sci 2:109-124

Novalic S, Jagschits F, Okwor J, Kulbe KD (1995) Behaviour of citric acid during electrodialysis. J Memb Sci 108:201-205

Novalic S, Okwor J, Kulbe KD (1996) The characteristics of citric acid separation using electrodialysis with bipolar membranes. Desalination 105(277):282

Oener SZ, Foster MJ, Boettcher SW (2020) Accelerating water dissociation in bipolar membranes and for electrocatalysis. Science. https://doi.org/10.1126/science.aaz1487

Okino S, Inui M, Yukawa H (2005) Production of organic acids by Corynebacterium glutamicum under oxygen deprivation. Appl Microbiol Biotechnol 68:475-480

Papagianni M, Mattey M, Kristiansen B (1999) The influence of glucose concentration on citric acid production and morphology of Aspergillus niger in batch and culture. Enzyme Microb Technol 25:710-717

Passoth V, Sandgren M (2019) Biofuel production from straw hydrolysates: current achievements and perspectives. Appl Microbiol Biotechnol 103:5105-5116

Pinazo JM, Domine ME, Parvulescu V, Petru F (2015) Sustainability metrics for succinic acid production: a comparison between biomass-based and petrochemical routes. Catal Today 239:17-24

Preiss L, Hicks DB, Suzuki S et al (2015) Alkaliphilic bacteria with impact on industrial applications, concepts of early life forms, and bioenergetics of ATP synthesis. Front Bioeng Biotechnol. https:// doi.org/10.3389/fbioe.2015.00075

Prikaznov AV, Shmal'Ko AV, Sivaev IB et al (2011) Synthesis of carboxylic acids based on the closo-decaborate anion. Polyhedron 30:1494-1501

Probstein RF, Sonin AA, Gur-Arie E (1972) A turbulent flow theory of electrodialysis. Desalination 11:165-187

Prochaska K, Woźniak-Budych MJ (2014) Recovery of fumaric acid from fermentation broth using bipolar electrodialysis. J Memb Sci 469:428-435

Rane KD, Sims KA (1993) Production of citric acid by Candida lipolytica Y1095: effect of glucose concentration on yield and productivity. Enzyme Microb Technol 15:646-651

Rawn DJ, Ouellette R (2018) Organic Chemistry: Structure, Mechanism, Synthesis. John Fedor

Riscaldati E, Moresi M, Federici F, Petruccioli M (2000) Direct ammonium fumarate production by Rhizopus arrhizus under phosphorous limitation. Biotechnol Lett 22:1043-1047

Sanchez S, Demain AL (2008) Metabolic regulation and overproduction of primary metabolites. Microb Biotechnol 1:283-319

Sang R, Kucmierczyk P, Dühren R et al (2019) Synthesis of carboxylic acids by palladium-catalyzed hydroxycarbonylation. Angew Chemie Int Ed 58:14365-14373 
Sawant O, Mahale S, Ramchandran V et al (2018) Fungal Citric acid production using waste materials: a mini-review. J Microbiol Biotechnol Food Sci 8:821-828

Sharma A, Parashar D, Satyanarayana T (2016) Acidophilic Microbes: Biology and Applications. In: Biotechnology of Extremophiles. pp 215-241

Solmi M V., Schmitz M, Leitner W (2019) CO 2 as a Building Block for the Catalytic Synthesis of Carboxylic Acids. In: Studies in Surface Science and Catalysis. pp 105-124

Sridhar S (1988) Application of electrodialysis in the production of malic acid. J Memb Sci 36:489-495

Stanko RT, Robertson RJ, Galbreath RW et al (1990) Enhanced leg exercise endurance with a high-carbohydrate diet and dihydroxyacetone and pyruvate. J Appl Physiol 69:1651-1656

Stanko RT, Tietze DL, Arch JE (1992) Body composition, energy utilization, and nitrogen metabolism with a $4.25-\mathrm{MJ} / \mathrm{d}$ low-energy diet supplemented with pyruvate. Am J Clin Nutr 56:630-635

Stanko RT, Reynolds HR, Hoyson R et al (1994) Pyruvate supplementation of a low-cholesterol, low-fat diet: effects on plasma lipid concentrations and body composition in hyperlipidemic patients. Am J Clin Nutr 59:423-427

Stoller M, Sacco O, Vilardi G et al (2018) Technical-economic evaluation of chromium recovery from tannery wastewater streams by means of membrane processes. Desalin Water Treat 127:57-63

Strathmann H, Grabowski A, Eigenberger G (2013) Ion-exchange membranes in the chemical process industry. Ind Eng Chem Res 52:10364-10379

Sun X, Lu H, Wang J (2017) Recovery of citric acid from fermented liquid by bipolar membrane electrodialysis. J Clean Prod 143:250-256

Szczygiełda M, Antczak J, Prochaska K (2017) Separation and concentration of succinic acid from post-fermentation broth by bipolar membrane electrodialysis (EDBM). Sep Purif Technol 181:53-59

Tian W, Wang X, Fan C, Cui Z (2019) Optimal treatment of hypersaline industrial wastewater via bipolar membrane electrodialysis. ACS Sustain Chem Eng 7:12358-12368

Timbuntam W, Sriroth K, Piyachomkwan K, Tokiwa Y (2008) Application of bipolar electrodialysis on recovery of free lactic acid after simultaneous saccharification and fermentation of cassava starch. Biotechnol Lett 30:1747-1752

Tongwen X, Weihua Y (2002) Effect of cell configurations on the performance of citric acid production by a bipolar membrane electrodialysis. J Memb Sci 203:145-153

Trchounian A, Trchounian K (2019) Fermentation revisited: how do microorganisms survive under energy-limited conditions? Trends Biochem Sci 44:391-400

Tronc JS, Lamarche F, Makhlouf J (1998) Effect of pH variation by electrodialysis on the inhibition of enzymatic browning in cloudy apple juice. J Agric Food Chem 46:829-833

van Linden N, Bandinu GL, Vermaas DA et al (2020) Bipolar membrane electrodialysis for energetically competitive ammonium removal and dissolved ammonia production. J Clean Prod. https:// doi.org/10.1016/j.jclepro.2020.120788

Wang Y, Huang C, Xu T (2011) Which is more competitive for production of organic acids, ion-exchange or electrodialysis with bipolar membranes? J Memb Sci 374:150-156

Wang X, Wang Y, Zhang X et al (2013) In-situ combination of fermentation and electrodialysis with bipolar membranes for the production of lactic acid: continuous operation. Bioresour Technol $147: 442-448$
Wang B, Zhao S, Tan F et al (2020) A novel green production process of citric acid on the pilot scale by directly recycling its extraction effluent. J Clean Prod. https://doi.org/10.1016/j.jclepro.2020. 124068

Whittington PN (1990) Fermentation broth clarification techniques. Appl Biochem Biotechnol 23:91-121

Woźniak MJ, Prochaska K (2014) Fumaric acid separation from fermentation broth using nanofiltration (NF) and bipolar electrodialysis (EDBM). Sep Purif Technol 125:179-186

Xu Q, Li S, Huang H, Wen J (2012) Key technologies for the industrial production of fumaric acid by fermentation. Biotechnol Adv 30:1685-1696

Xue S, Wu C, Wu Y et al (2015) Bipolar membrane electrodialysis for treatment of sodium acetate waste residue. Sep Purif Technol 154:193-203

Yan Z, Zhu L, Li YC et al (2018) The balance of electric field and interfacial catalysis in promoting water dissociation in bipolar membranes. Energy Environ Sci 11:2235-2245

Yan H, Li W, Zhou Y et al (2020) In-situ combination of bipolar membrane electrodialysis with monovalent selective anion-exchange membrane for the valorization of mixed salts into relatively highpurity monoprotic and diprotic acids. Membranes (basel) 10:1-15

Yin X, Li J, Shin H, dong et al (2015) Metabolic engineering in the biotechnological production of organic acids in the tricarboxylic acid cycle of microorganisms: advances and prospects. Biotechnol Adv 33:830-841

Yu Q, Li Y, Wu B et al (2020) Novel mutagenesis and screening technologies for food microorganisms: advances and prospects. Appl Microbiol Biotechnol. https://doi.org/10.1007/ s00253-019-10341-z

Zeikus JG, Jain MK, Elankovan P (1999) Biotechnology of succinic acid production and markets for derived industrial products. Appl Microbiol Biotechnol 51:545-552

Zelić B, Vasić-Rački D (2005) Process development and modeling of pyruvate recovery from a model solution and fermentation broth. Desalination 174:267-276

Zelić B, Gerharz T, Bott M et al (2003) Fed-batch process for pyruvate production by recombinant escherichia coli yyc202 strain. Eng Life Sci 3:299-305

Zhang X, Wang X, Shanmugam KT, Ingram LO (2011) L-malate production by metabolically engineered Escherichia coli. Appl Environ Microbiol 77:427-434

Zhao W, Jegatheesan V, Liang Q et al (2021a) Towards high carbon conversion efficiency by using a tailored electrodialysis process for in-situ carboxylic acids recovery. J Clean Prod. https://doi.org/ 10.1016/j.jclepro.2021.126431

Zhao Z, Li Y, Jin D, Van der Bruggen B (2021b) Modification of an anion exchange membrane based on rapid mussel-inspired deposition for improved antifouling performance. Colloids Surfaces A Physicochem Eng Asp. https://doi.org/10.1016/j.colsurfa.2021. 126267

Zhou Y, Du J, Tsao GT (2002) Comparison of fumaric acid production by Rhizopus oryzae using different neutralizing agents. Bioprocess Biosyst Eng 25:179-181

Publisher's Note Springer Nature remains neutral with regard to jurisdictional claims in published maps and institutional affiliations. 